\title{
Hubungan Kesegaran Jasmani Dengan Kemampuan Shooting dalam Permainan Sepak Bola pada Pemain PS. Andeskal Muda Kota Bengkulu
}

\section{R. Syaputra ${ }^{1, a)}$}

\section{Affiliation:}

1. Program Studi Pendidikan

Jasmani FKIP UNIVED

Bengkulu

Corresponding Author:

a.

Roniiisyaputraaa17@gmail.com

\section{Abstract}

This study aims to determine the relationship of Physical Freshness and Shooting Ability in Football Games on PS Players. Andeskal Muda City of Bengkulu. This type of research is correlational with quantitative methods. The population in this study were PS players. Andeskal Muda Bengkulu City, amounting to 30 people. While the sampling technique was done by using the total sampling technique. Thus, the sample size is 30 people. Data was collected using the Indonesian Physical Fitness Test (TKJI) and the shooting ability test was carried out by the shooting at the ball test. The level of physical fitness of PS players. Andeskal city of Bengkulu had the lowest score of 11 categories with less and the highest score of 22 which was very good category, and the shooting ability had the lowest score of 24 poor categories and the highest score was 47 which was very good category. The results showed that the level of physical fitness of the players had a relationship with the results of the shooting ability of the PS players. Andeskal Muda city of Bengkulu, based on the value of rtable in the product moment obtained 0.361 then rejected Ho in the $t$ analysis test obtained, tcount was 6.1978 greater than ttable is 2.048, the decision rejected the alternative hypothesis (Ho) and accepted the alternative hypothesis (Ha). So the conclusion is that there is a correlation between the TKJI test (variable $x$ ) and the shooting ability test (variable y) on PS players. Andeskal Muda city of Bengkulu, this is shown by the correlation coefficient of 0.76 which is in the strong category.

Keyword: Physical freshness; Shooting ability 


\section{Pendahuluan}

Klub Andeskal Muda merupakan salah satu klub sepak bola yang berada di kandang limun, unib belakang yang bermain di Liga Kota Bengkulu (LKBB) divisi satu dengan prestasi yang pernah didapat yaitu peringkat 9 di divisi satu liga kota Bengkulu. Untuk mencapai suatu perestasi pada setiap cabang olahraga, maka di dirikanlah klub-klub sebagai tempat menjaring atau menciptakan atlet berprestasi dengan menerapkan teknik dasar seperti shooting, passing, drible.

Klub Andeskal Muda adalah salah satu klub sepak bola yang ada di provinsi bengkulu yang berdiri pada tahun 2008 dengan nama Karin (Karya Beringin), setelah itu pada tahun 2010 mengalami perubahan nama menjadi PS. Andeskal Muda yang mengikuti kompetensi di divisi satu dengan pelatih Agusrin dan menejer Ciex Pani. Para pemain yang direkrut oleh klub Andeskal Muda ini banyak berasal dari daerah unib belakang yang kebanyakannya merupakan orang unib belakang, yang tentunya diadakan seleksi terlebih dahulu. Klub Andeskal Muda ini sudah cukup lama berdiri dan sudah banyak prestasi yang diperoleh, tetapi sekarang prestasi klub Andeskal Muda menurun, sehingga dilakukanlah pembenahan disegala bidang. Diantara penyebab kemerosotan adalah minimnya pengalaman bertanding para pemain dan kurangnya memanfaatkan waktu untuk menjaga kesegaran jasmani dan kurangnya menguasai skill dan teknik dasar bermain sepak bola seperti : 1) menembak bola ke arah gawang (shooting), 2) menendang bola (passing), 3) menggiring bola (dribbling) , 4) menghentikan bola (trapping), dan 5) menyundul bola (heading), dimana masingmasingnya mempunyai tujuan dan fungsi yang berbeda.

Dari sudut pandang penyerang, tujuan sepak bola adalah melakukan shooting ke gawang. Seluruh pemain harus menguasai keterampilan dasar menendang bola dan selanjutnya mengembangkan sederetan teknik shooting yang memungkinkannya untuk melakukan tendangan shooting dan mencetak gol dari berbagai posisi di lapangan ( Mielke, 2007 : 67).

Setiap pemain harus mampu melakukan shooting (menembak), kerena tembakan merupakan bagian penting dalam sepak bola. Untuk dapat melakukan shooting yang efektif dibutuhkan banyak faktor di antaranya, keseimbangan, perkenaan kaki dengan bola, daya ledak otot tungkai, kesegaran jasmani dan lainlain.

Kesegaran jasmani merupakan kebutuhan setiap manusia dalam melangsungkan dan mempertahankan kehidupannya dan juga merupakan kesanggupan dalam melakukan aktivitas dan kemampuan menyesuaikan diri terhadap pekerjaan adalah kemampuan menyesuaikan diri terhadap pekerjaan adalah alternatif yang sebenarnya dimulai dari kesegaran jasmani. Selain dari pada itu dapat dengan tangkas dalam melakukan pekerjaan tanpa banyak mengalami kelelahan yang berarti, dan masih mempunyai sisa cadangan tenaga yang berarti untuk menikmati waktu senggangnya untuk keperluan-keperluan lainnya.

Arsil (1999: 14) mengatakan bahwa komponen-komponen kesegaran jasmani meliputi : 1) daya tahan (endurance), 2) kekuatan otot (muscle strength), 3) daya otot (muscle strength), 4) kelenturan (fleksibility), 5) kecepatan (speed), 6) kelincahan (agility), 7) Keseimbangan (belance), 8) koordinasi (coordination), 9) ketepatan (accuracy).

Dari hasil pengamatan peneliti di lapangan, bahwa kesegaran jasmani dengan kemampuan shooting pada pemain PS. Andeskal Muda belum baik.

Berdasarkan uraian diatas maka penulis sangat tertarik untuk meneliti mengenai "Hubungan kesegaran jasmani dengan kemampuan shooting dalam permainan sepak bola pada pemain PS. Andeskal Muda kota Bengkulu”.

\section{Metode Penelitian}

Metode yang digunakan dalam penelitian ini adalah penelitian kuantitatif dengan jenis penelitian korelasional, sebagaimana yang dikemukakan (Dewi L. Badriah, 2006 : 53) Tujuan penelitian korelasional adalah untuk mendeteksi sejauh mana variasi-variasi pada satu atau lebih faktor lain tanpa melakukan intervensi tertentu terhadap variasi variabel - variabel yang bersangkutan. Keeratan hubungan didasarkan pada koefisien korelasi yang diperoleh dari setiap variabel penelitian yang dianalisis.

\section{Hasil Penelitian}

\section{Deskripsi Data}

Untuk mencapai tujuan penelitian yang berjudul hubungan kesegaran jasmani dengan kemampuan shooting dalam permainan sepak bola pada pemain PS. Andeskal Muda kota 
Bengkulu tahun 2015 dilakukan penggumpulan data. Data merupakan hasil tes dan pengukuran didalam penelitian ini tes yang digunakan adalah tes Kesegaran Jasmani Indonesia (TKJI) dan tes kemampuan shooting, sedangkan untuk tes TKJI terdiri dari 5 pos tes yaitu : 1) lari cepat jarak 50 dan 60 meter, 2) angkat tubuh selama 60 detik, 3) baring duduk selama 60 detik, 4) loncat tegak, 5) lari jarak 1000 dan 1200 meter.

Berdasarkan dari hasil tes kesegaran jasmani dan kemampuan shooting dalam permainan sepak bola pemain PS. Andeskal Muda kota Bengkulu, maka diperoleh nilai rata-rata, nilai maksimal dan nilai minimal yang yang diperoleh pemain PS. Andeskal Muda pada masing-masing tes yang dilakukan. Untuk lebih jelasnya dapat diperhatikan pada tabel dibawah ini :

Tabel 1 Deskripsi Data

\begin{tabular}{|c|c|c|c|c|c|}
\hline Nama Tes & $\begin{array}{c}\text { Jumla } \\
\mathrm{h} \\
\text { Hasil } \\
\text { Tes }\end{array}$ & $\begin{array}{c}\text { Nilai } \\
\text { Tertin } \\
\text { gi }\end{array}$ & $\begin{array}{c}\text { Nilai } \\
\text { Terend } \\
\text { ah }\end{array}$ & $\begin{array}{c}\text { Nila } \\
\text { i } \\
\text { Rat } \\
\text { a- } \\
\text { Rat } \\
\text { a }\end{array}$ & $\begin{array}{c}\text { Norm } \\
\text { a } \\
\text { Penil } \\
\text { aian }\end{array}$ \\
\hline $\begin{array}{c}\text { Kesegaran } \\
\text { Jasmani }\end{array}$ & 441 & 22 & 11 & 14,7 & $\begin{array}{c}\text { Sedan } \\
\text { g }\end{array}$ \\
\hline $\begin{array}{c}\text { Kemampu } \\
\text { an } \\
\text { Shooting }\end{array}$ & 1046 & 47 & 24 & 34,8 & Baik \\
667 & & & & \\
\hline
\end{tabular}

\section{Analisis Data}

Sebelum melaksanakan penelitian dilakukan pencatatan nama-nama testi pemain PS. Andeskal Muda kota Bengkulu yang berjumlah 30 orang. Keseluruhan pemain yang dijadikan populasi sebanyak 30 orang yaitu terdiri dari laki-laki semua yang berusia antara 13-19 tahun sesuai instrumen tes tingkat kesegaran jasmani indonesia yang berusia 13-19 tahun. Seperti dibawah ini norma tes TKJI. 


\begin{tabular}{|c|c|c|c|c|c|}
\hline & \multicolumn{5}{|l|}{ 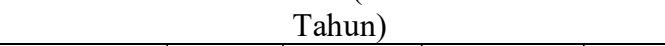 } \\
\hline $\begin{array}{c}\text { Lari } \\
50 \\
\text { Meter }\end{array}$ & $\begin{array}{c}\text { Gantung } \\
\text { Angkat } \\
\text { Tubuh }\end{array}$ & $\begin{array}{c}\text { Barin } \\
\text { g } \\
\text { Dudu } \\
\text { k }\end{array}$ & $\begin{array}{c}\text { Loncat } \\
\text { Tegak }\end{array}$ & $\begin{array}{c}\text { Lari } \\
1000 \\
\text { Meter }\end{array}$ & $\begin{array}{c}\text { Nila } \\
\text { i }\end{array}$ \\
\hline $\begin{array}{l}\text { S.d - } \\
6,7^{\prime \prime}\end{array}$ & 16- Keatas & $\begin{array}{c}\text { 38- } \\
\text { Keata } \\
\text { s }\end{array}$ & $\begin{array}{c}66 \\
\text { Keatas }\end{array}$ & $\begin{array}{l}\text { s.d - } \\
\text { 3'04', }\end{array}$ & 5 \\
\hline $\begin{array}{c}6.8^{\prime \prime} \\
- \\
7,6 "\end{array}$ & $11-15$ & $\begin{array}{c}28- \\
37\end{array}$ & $53-65$ & $\begin{array}{c}\text { 3'05' - } \\
\text { 3'53'" }\end{array}$ & 4 \\
\hline $\begin{array}{c}7,7^{\prime \prime} \\
- \\
8,7 ”\end{array}$ & $6-10$ & $\begin{array}{c}19- \\
27\end{array}$ & $42-52$ & $\begin{array}{c}\text { 3'54" - } \\
\text { 4'46" }\end{array}$ & 3 \\
\hline $\begin{array}{l}8,8 "- \\
10,3 "\end{array}$ & $2-5$ & $\begin{array}{l}8- \\
18\end{array}$ & $31-41$ & $\begin{array}{c}\text { 4'47'"- } \\
\text { 6'04"' }\end{array}$ & 2 \\
\hline $\begin{array}{l}10,4 " \\
-d s t\end{array}$ & $0-1$ & $0-7$ & $0-30$ & $\begin{array}{c}\text { 6'05"- } \\
\text { dst }\end{array}$ & 1 \\
\hline
\end{tabular}

Sumber : Arsil (2010: 75)

Tabel 3 Norma Nilai TKJI (Untuk Putra Usia 16-19 Tahun)

\begin{tabular}{|c|c|c|c|c|c|}
\hline $\begin{array}{l}\text { Lari } 60 \\
\text { Meter }\end{array}$ & $\begin{array}{c}\text { Gantun } \\
\text { g } \\
\text { Angkat } \\
\text { Tubuh }\end{array}$ & $\begin{array}{l}\text { Baring } \\
\text { Duduk }\end{array}$ & $\begin{array}{c}\text { Lonc } \\
\text { at } \\
\text { Tega } \\
\mathrm{k}\end{array}$ & $\begin{array}{c}\text { Lari } \\
1200 \\
\text { Meter }\end{array}$ & $\begin{array}{c}\text { Nila } \\
\text { i }\end{array}$ \\
\hline $\begin{array}{l}\text { S.d - } \\
7,2 "\end{array}$ & $\begin{array}{c}19 \text { - } \\
\text { Keatas }\end{array}$ & $\begin{array}{c}41- \\
\text { Keatas }\end{array}$ & $\begin{array}{c}73 \\
\text { Keata } \\
\text { s }\end{array}$ & $\begin{array}{l}\text { s.d - } \\
\text { 3'14" }\end{array}$ & 5 \\
\hline $\begin{array}{l}\text { 7.3" }- \\
8,3 "\end{array}$ & $14-18$ & $30-40$ & $\begin{array}{c}60- \\
72\end{array}$ & $\begin{array}{c}\text { 3'15' } \\
- \\
\text { 4'25' }\end{array}$ & 4 \\
\hline $\begin{array}{c}8,4 "- \\
9,6 "\end{array}$ & $9-13$ & $21-29$ & $\begin{array}{c}50- \\
59\end{array}$ & $\begin{array}{c}4^{\prime} 26^{\prime \prime} \\
- \\
5^{\prime} 12^{\prime \prime}\end{array}$ & 3 \\
\hline $\begin{array}{l}9,7 "- \\
11,0 "\end{array}$ & $5-8$ & $10-20$ & $\begin{array}{c}39- \\
49\end{array}$ & $\begin{array}{c}\text { '13' } \\
- \\
\text { 6'33' }\end{array}$ & 2 \\
\hline $11,1 " \mathrm{dst}$ & $0-4$ & $0-9$ & $38 \mathrm{dst}$ & $\begin{array}{c}\text { 6'34" } \\
\text { dst }\end{array}$ & 1 \\
\hline
\end{tabular}

Sumber : Arsil (2010: 75)

Tabel 4 NORMA TES KESEGARAN JASMANI INDONESIA

\begin{tabular}{|c|c|c|}
\hline No & Jumlah Nilai & $\begin{array}{c}\text { Klasifikasi Kesegaran } \\
\text { Jasmani }\end{array}$ \\
\hline 1. & $22-25$ & Baik sekali (BS ) \\
\hline 2. & $18-21$ & Baik ( B ) \\
\hline 3. & $14-17$ & Sedang ( S ) \\
\hline 4. & $10-13$ & Kurang ( K ) \\
\hline 5. & $5-9$ & Kurang sekali ( KS ) \\
\hline \multicolumn{3}{|c|}{ Sumber : Arsil, (2010:78) }
\end{tabular}

1) Uji Prasyarat Data TKJI dan Kemampuan Shooting

1. Uji Normalitas

Uji normalitas TKJI pemain PS. Andeskal Muda kota Bengkulu Nilai $x^{2}=9,6$ sedangkan nilai $x^{2}$ tabel adalah 43,773 Maka nilai $x^{2}$ hitung 9,6 S dari $\mathrm{x}^{2}$ tabel 43,773 Normal , dan Uji normalitas kemampuan shooting pemain PS. Andeskal Muda kota Bengkulu diperoleh Nilai $\mathrm{x}^{2}$ $=36,4$ sedangkan nilai $\mathrm{x}^{2}$ tabel adalah 43,773 Maka nilai $x^{2}$ hitung $36,4 \leq x^{2}$ tabel 43,773 Normal Krtiteria :

Jika $\mathrm{x}$ hitung $\geq \mathrm{x}^{2}$ tabel, maka distribusi data tidak normal

Jika $\mathrm{x}^{2}$ hitung $\leq \mathrm{x}^{2}$ tabel, maka distribusi data normal

2. Uji Homogenitas

Uji homogenitas dengan menggunakan Uji Varians ;

Fhitung $=\frac{\text { Varian Terbesar }}{\text { Varian Terkecil }}=\frac{17,98}{10,24}=1,75$

Jika Fhitung $\leq$ Ftabel maka data homogen

Jika Fhitung $\geq$ Ftabel maka data tidak homogen

Maka nilai Fhitung $1,75 \leq$ Ftabel 1,85

\section{Homogen}

Membandingkan Fhitung dengan Ftabel pada tabel distribusi $\mathrm{F}$, dengan varians terbesar adalah $\mathrm{dk}$ pembilang $\mathrm{n}-1$. Untuk varians terkecil adalah $\mathrm{dk}$ penyebut $\mathrm{n}-1$. Jika Fhitung $\leq$ Ftabel berarti homogen. Jika Fhitung $\geq$ Ftabel berarti tidak homogen. Yaitu varians terbesar adalah $\mathrm{dk}$ pembilang $30-1=29$, sedangkan untuk varians terkecilnya adalah $\mathrm{dk}$ penyebut $30-1=29$, dan terdapat hasil Fhitung adalah 1,75 dan Ftabel adalah 1,85 berarti data homogen.

\section{Uji Korelasional}

Uji korelasi dilakukan untuk mengetahui apakah ada hubungan yang signifikan antara kesegaran jasmani dengan kemampuan shooting dalam permainan sepak bola pada pemain PS. Andeskal Muda kota Bengkulu. Uji korelasi ini menggunakan rumus pearson product moment. Sebelum data dimasukan kedalam rumus tersebut maka terlebih dahulu dibuat tabel kerja. Setelah dibuat tabel kerja korelasi Kesegaran Jasmani dengan kemampuan shooting sepak bola pada pemain PS. Andeskal Muda kota Bengkulu, maka diperoleh $\sum X=441, \sum Y=1046, \sum X^{2}=6781$, $\sum Y^{2}=$ 36992, $\sum X Y=15676$, langkah selanjutnya dimasukan kedalam rumus pearson product 
moment dan di lanjutkan dengan pengujian hipotesis.

Perhitungan dengan menggunakan rumus pearson product moment

$$
\begin{aligned}
& \text { Rxy }=\frac{n \cdot \sum X Y-\left(\sum X\right)\left(\sum Y\right)}{\sqrt{\left\{n \cdot \sum X^{2}-\left(\sum X\right)^{2}\right\}\left\{n \cdot \sum Y^{2}-\left(\sum Y\right)^{2}\right\}}} \\
& \operatorname{Rxy}=\frac{30.15676-(441)(1046)}{\sqrt{\left\{30.6781-(441)^{2}\right\}\left\{30.36992-(1046)^{2}\right\}}} \\
& \operatorname{Rxy}=\frac{470280-461286}{\sqrt{\{203430-194481\}\{1109760-1094116\}}} \\
& \operatorname{Rxy}=\frac{8994}{\sqrt{\{8949\}\{15644\}}}=\frac{8994}{\sqrt{139998156}}=\frac{8994}{11832,08}
\end{aligned}
$$
$=0,76$

Berdasarkan perhitungan diatas diperoleh nilai rhitung sebesar 0,76 sedangkan rtabel pada $\alpha=$ $5 \%$ dan $\mathrm{dk}=\mathrm{n}-2=30-2=28$ adalah 0,374 (pada tabel r). Untuk mengetahui lebih lanjut keeratan hubungan antara kedua variabel tersebut, kemudian pengujian dilanjutkan dengan uji t, yaitu sebagai berikut :

$$
\begin{array}{rl}
\mathrm{t} & =\frac{r \sqrt{(n-2)}}{\sqrt{1-r^{2}}} ; \\
28 & \mathrm{db}=\mathrm{n}-2=30-2 \\
\mathrm{t} & =\frac{0,76 \sqrt{30-2}}{\sqrt{1-0,76^{2}}}=\frac{0,76 \sqrt{28}}{\sqrt{1-0,5776}} \\
\mathrm{t} & =\frac{0,76.5,3}{\sqrt{0,4224}}=\frac{4,028}{0,6499}=6,1978
\end{array}
$$

Ttabel (dilampirkan ) pada $\alpha=5 \%$ dengan $\mathrm{db}$ 28 adalah 2,048. Dari analisis diatas maka diperoleh bahwa thitung $\geq$ ttabel yaitu $6,1978 \geq$ 2,048, maka dengan demikian dapat dikatakan bahwa terdapat hubungan erat antara kesegaran jasmanai dengan kemampuan shooting dalam permianan sepak bola pada pemain PS. Andeskal Muda kota Bengkulu.

\section{Pembahasan}

Berdasarkan hasil tes kesegaran jasmani dan kemampuan shooting, bahwa tingkat kesegaran jasmani pemain PS. Andeskal Muda kota Bengkulu memiliki tingkat kesegaran jasmani pada kategori sedang yaitu dengan rata-rata 14,7. Dan yang memperoleh norma tes di kategori baik sekali sebanyak 2 orang, dan yang berkategori baik sebanyak 2 orang, sedangkan berkategori sedang sebanyak 14 orang, dan yang mendapat nilai berkategori kurang sebanyak 12 orang. Nilai tertinggi adalah 22 dan nilai terendah adalah 11 . Kesegaran jasmani didapat hasil $X^{2}$ adalah 9,6 sedangkan $X^{2}$ tabel adalah 43,773 yang berati ditribusi normal. Sedangkan tingkat kemampuan shooting pemain PS. Andeskal Muda kota Bengkulu memiliki tingkat kemampuan pada kategori baik yaitu dengan rata-rata 34,8667. Dan yang memperoleh norma tes di kategori baik sekali sebanyak 2 orang, dan yang berkategori baik sebanyak 20 orang, sedangkan berkategori sedang sebanyak 7 orang, dan yang mendapat nilai berkategori kurang sebanyak 1 orang. Dapat diketahui bahwa rata-rata penelitian yang mendapatkan hasil skor yaitu di norma tes kemampuan Shooting At The Ball 34,8667, sedangkan nilai tertinggi adalah 47 dan nilai terendah adalah 24 kemampuan shooting didapat hasil $\mathrm{X}^{2}$ hitung adalah 36,4 sedangkan $\mathrm{X}^{2}$ tabel adalah 43.773 yang berati ditribusi normal. Dan hasil uji homogenitas mendapatkan hasil Fhitung adalah 1,75 dan Ftabel adalah 1,85. Berarti Fhitung $1,75<$ dari Ftabel 1,85 maka data distribusi Homogen. Sedangkan hubungan antara kesegaran jasmani terhadap kemampuan shooting sepak bola berdasarkan uji korelasi product moment dengan simpangan antara tes TKJI dengan Kemampuan shooting pada pemain PS. Andeskal Muda adalah 0,76 pada posisi katagori kuat (tinggi). Sedangkan nilai ttabel ditentukan berdasarkan tingkat signifikansi $(\alpha)$ adalah $5 \%$ yang digunakan dan derajat kebebasan $($ d.f $=n-2$ ) yang besarnya sampel (n) adalah 30, maka d.f = $30-2=28$ berdasarkan distribusi ttabel diperoleh 2,048. Keputusan diambil dengan jalan membandingkan nilai thitung dengan ttabel. Jika thitung lebih kecil dari ttabel, maka keputusan menerima hipotesis Ho. Dan sebaliknya jika thitung lebih besar dari ttabel maka menolak Ho dan menerima $\mathrm{Ha}$, pada pengujian ini , thitung adalah 6,1978 lebih besar dari pada ttabel adalah 2,048, maka keputusan menolak hipotesis nol (Ho) dan menerima hipotesis alternatif (Ha). Maka kesimpulannya adalah terdapat korelasi antara variabel $\mathrm{x}$ dan variabel $\mathrm{y}$. Yaitu terdapat hubungan antara Kesegaran Jasmani dengan Kemampuan Shooting dalam permainan sepak bola pada pemain PS. Andeskal Muda kota Bengkulu.

Kesegaran Jasmani yang baik dapat mempermudah penguasaan teknik bermain secra efektif dan efesien di dalam penempatan bola secara cepat dan tepat kearah sasaran, sudut gawang atau ke daerah yang sulit dijangkau atau ditangkap oleh penjaga gawang lawan sehingga dapat menghasilkan gol. Namun sebaliknya, apabila seorang pemain tidak memiliki kesegaran jasmani dengan baik maka tidak dapat melakukan shooting bola dengan baik sehingga tidak tepat pada sasaran yang diinginkan dan menciptakan gol. 
Danny Mielke (2007 :67) Shooting merupakan teknik yang sangat penting dalam permainan sepak bola untuk mencapai tujuan dari permainan sepak bola itu sendiri yaitu menciptakan gol sebanyak-banyaknya kegawang lawan dan Shooting merupakan teknik yang sangat penting dalam permainan sepak bola untuk mencapai tujuan dari permainan sepak bola itu sendiri yaitu menciptakan gol sebanyak-banyaknya kegawang lawan dan mempertahankan gawang dari kebobolan.

Hasil penelitian membuktikan bahwa terdapat hubungan secara signifikan antara kesegaran jasmani dengan kemampuan shooting sepak bola pada pemain PS. Andeskal Muda kota Bengkulu dengan koefisien korelasi adalah 0,76.

\section{Kesimpulan}

Hasil penelitian tentang hubungan kesegaran jasmani dengan kemampuan shooting dalam permainan sepak bola pada pemain PS. Andeskal Muda kota Bengkulu maka dapat diambil kesimpulan sebagai beriut :

1. Bahwa tingkat kesegaran jasmani pemain PS. Andeskal Muda kota Bengkulu memiliki tingkat kesegaran jasmani pada kategori sedang yaitu dengan rata-rata 14,7 . Dan yang memperoleh norma tes di kategori baik sekali sebanyak 2 orang, dan yang berkategori baik sebanyak 2 orang, sedangkan berkategori sedang sebanyak 14 orang, dan yang mendapat nilai berkategori kurang sebanyak 12 orang, sedangkan nilai tertinggi adalah 22 dan nilai terendah adalah 11 .

2. Tingkat kemampuan shooting pemain PS. Andeskal Muda kota Bengkulu memiliki tingkat kemampuan pada kategori baik yaitu dengan rata-rata 34,8667 . Dan yang memperoleh norma tes di kategori baik sekali sebanyak 2 orang, dan yang berkategori baik sebanyak 20 orang, sedangkan berkategori sedang sebanyak 7 orang, dan yang mendapat nilai berkategori kurang sebanyak 1 orang.

3. Tingkat kesegaran jasmani pemain memiliki hubungan dengan hasil kemampuan shooting pemain PS. Andeskal Muda kota Bengkulu, hal ini ditunjukan dengan koefisien korelasi 0,76 berada dikategori kuat, berdasarkan nilai $\mathrm{r}$ dalam product moment diperoleh 0,374 maka menolak Ho pada pengujian analisis $\mathrm{t}$ diperoleh, thitung adalah 6,1978 lebih besar daripada ttabel adalah 2,048, maka keputusan menolak hipotesis alternatif (Ho) dan menerima hipotesis alternatif ( $\mathrm{Ha})$. Maka kesimpulannya adalah terdapat korelasi antara varibel $\mathrm{x}$ dan variabel $\mathrm{y}$. Yaitu kesimpulannya terdapat hubungan antara tes TKJI dengan hasil kemampuan shooting pemain PS. Andeskal Muda kota Bengkulu dalam kategori kuat.

4. Hasil penelitian mengenai Hubungan Kesegaran Jasmani Dengan Kemampuan Shooting Dalam Permainan Sepak Bola Pada Pemain Ps. Andeskal Muda Kota Bengkulu. Mempunyai hubungan, teryata menunjukkan hubungan yang signifikan, kedua variabel tersebut memberikan hubungan sebesar 0,76.

Berdasarkan pada hasil penelitian di atas bahwa kesegaran jasmani memberikan hubungan yang berarti terhadap kemampuan shooting. Selama ini masalah pemain PS. Andeskal Muda kota Bengkulu adalah masih kurangnya upaya meningkatkan kesegaran jasmani dengan kemampuan shooting. Maka dalam mengatasi masalah tersebut, diperlukan adanya usaha dan upaya dari pihak pemain yang bersangkutan dan pelatih.

\section{Daftar Pustaka}

Arikunto Suharsimi. (2010). Manajemen Penelitian. Jakarta : Rineka Cipta.

Arsil. (1999). Evaluasi Pendidikan Jasmani dan Olahraga. Malang : Wineka Media.

Arsil. (2010). Evaluasi Pendidikan Jasmani dan Olahraga. Malang: Wineka Media.

Danny Mielke. (2007). Dasar-dasar sepak bola. Bandung : Human Kinetic.

Dewi L. Badriah. (2006). Metodologi Penelitian dan Imu-Ilmu Kesehatan. Bandung : Multazam.

Muhamad Isnadi. (2010). Perbedaan Tingkat Kesegaran Jasmani Siswa Ekonomi Kuat Dengan Siswa Ekonomi Lemah di Man Model 1 Kota Bengkulu, Bengkulu : Universitas Bengkulu.

Nurhasan. (2010). Tes dan Pengukuran Dalam Pendidikan Jasmani Prinsip-Prinsip dan Penerapannya. Jakarta: Direktorat Jendral Olahraga.

Robert Koger. (2007). Latihan Dasar Andal Sepak Bola Remaja. Yogyakarta : Saka Mitra Kompetensi.

Sudjana. (1996).Metoda Statistik, Edisi ke 5. Bandung: Tarsito.

Sugiyono. (2009). Metode Penelitian Kualitatif 
dan Kuantitatif $R \& D$. Bandung : Alfabeta.

Zidane Muhdhor Al-Hadiqie. (2013). Menjadi

Pemain Sepak Bola Profesional, teknik, strategi, dan taktik. Jakarta : Kata Pena. 